\title{
Role of complete laser photocoagulation and wide- field imaging in aggressive posterior retinopathy of prematurity
}

\author{
Deepika C Parameswarappa, Komal Agarwal, Subhadra Jalali, Agniv Datta
}

Vitreo-retina, LV Prasad Eye Institute, Hyderabad, India

\section{Correspondence to Dr Komal Agarwal, komal.agarwal.vr@gmail.com}

Accepted 28 April 2019

\section{DESCRIPTION}

A premature baby born at 28 weeks of gestation, post menstrual age (PMA) of 35 weeks, and birth weight of $1000 \mathrm{~g}$ presented to us with the diagnosis of aggressive posterior retinopathy of prematurity (APROP). The baby had a history of undergoing laser photocoagulation for the same at PMA of 33 weeks. On examination, retinae of both eyes showed dilation and tortuosity of vessels in zone 1 with haemorrhages and looping with avascular zones beyond. Both the retinae also showed evidence of previously treated sparse laser marks and skip areas in the anterior retinae with unlasered avascular areas in zone 2 (figure 1A,B). The wide-field digital imaging helped us in identification all the avascular and skip areas (figure 1A,B). It also played an important role as an educational tool for instructing our training ophthalmologists and fellows, and clearly delineate to them the areas which needed additional laser. Subsequently, the baby was treated with complete and aggressive photocoagulation for all the avascular and skip areas. One month post laser (39 weeks PMA), the retinae in both eyes showed reduced tortuosity and dilation of the vessels, resolved haemorrhages and regressed loops (figure 1C,D). The regression of the APROP picture was well seen and documented by wide-field digital imaging.
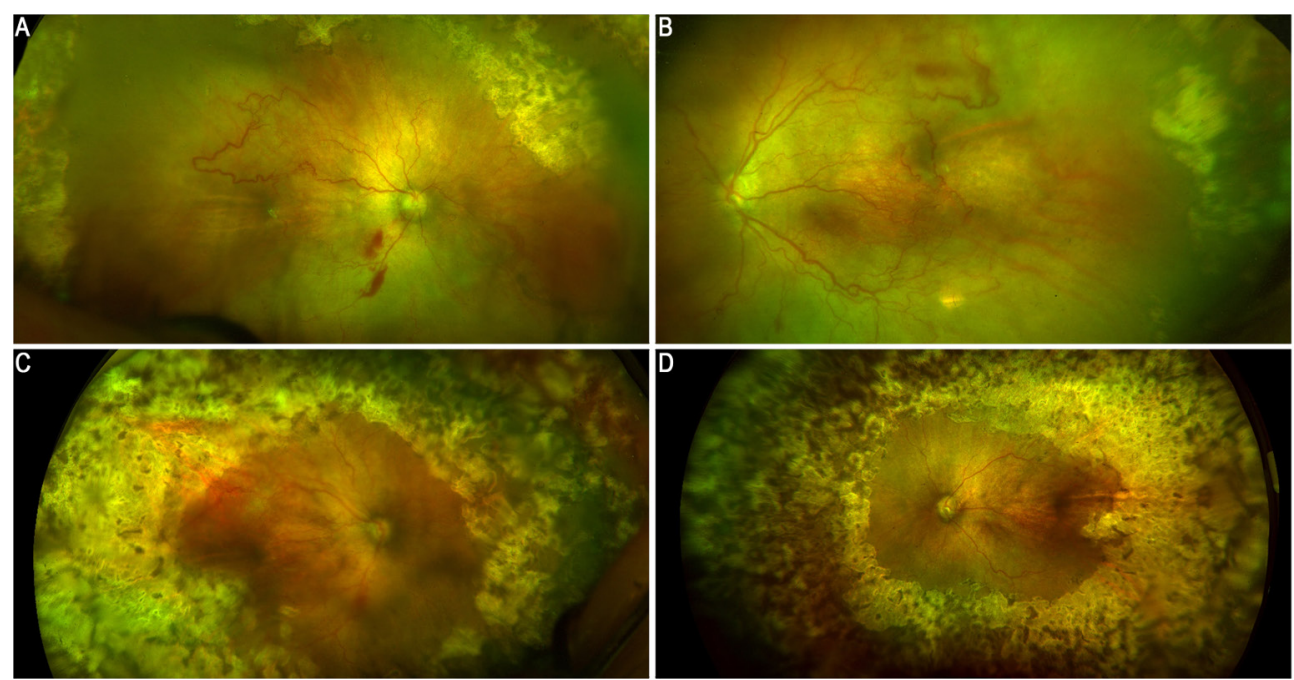

Figure 1 Ultra-wide-field colour fundus photographs. ( $A$, right eye) and ( $B$, left eye) Dilation and tortuosity of vessels in zone 1 with haemorrhages and looping with avascular zones beyond, previously treated sparse laser marks and skip areas in the anterior retina, with unlasered avascular areas in zone 2. (C, right eye) and (D, left eye) Post complete laser showing reduced tortuosity and dilation of the vessels, resolved haemorrhages and regressed loops.

Retinopathy of prematurity is one of the major causes of childhood blindness. ${ }^{1}$ APROP is characterised by severe plus disease, flat neovascularisation in zone 1 or posterior zone 2, intraretinal shunting, haemorrhages and a rapid progression to retinal detachment. ${ }^{2}$ Rigid pupil and neovascularisation of iris are not uncommon which preclude good visualisation. APROP needs immediate and aggressive treatment for its regression. ${ }^{1}$ Skip areas post incomplete laser lead to recurrence of the disease complicating into tractional retinal detachment. The challenge to perform a complete laser is further complicated by improper and difficult visualisation of paediatric eyes. The visualisation of the retina and proper identification is made easy by newer wide-field imaging of paediatric eyes. The Optos widefield imaging system (Optos camera; Optos, Dunfermline, UK) uses confocal scanning laser ophthalmoscopes with ellipsoid mirrors to create images of up to $200^{\circ}$ of the retinal periphery and can be used through even in a non-mydriatic pupil. These images can be of great value in paediatric patients, in whom fundus view is challenging. Digital imaging can assist ophthalmologists in visualising all regions of the retina and quick identification of lasered and unlasered skip areas. ${ }^{34}$ Moreover, digital imaging is an important educational tool for training ophthalmologists and

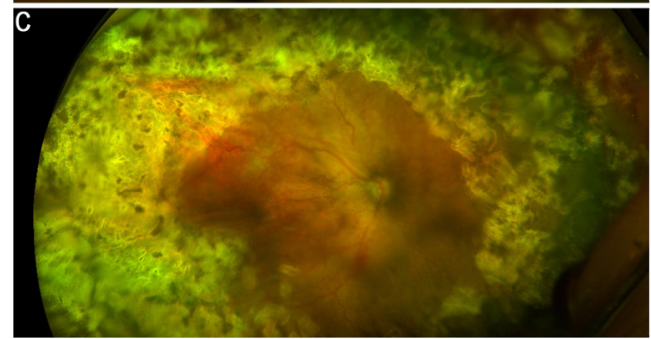

C Parameswarappa D,

Agarwal K, Jalali $S$, et al. BMJ Case Rep 2019;12:e230031. doi:10.1136/bcr-2019-

230031 
fellows who face the maximum challenge in paediatric retinal examination and its photocoagulation.

\section{Learning points}

- Wide-field imaging is an important education tool for training ophthalmologists and fellows. It removes the barrier of difficult learning curves.

- Wide-field digital imaging is an excellent tool in viewing the paediatric retina.

- APROP needs an early, complete and aggressive laser treatment to all the avascular areas for complete regression.

Contributors DCP: acquisition of images, concept and design, manuscript writing. KA: acquisition of images, concept and design, editing and approval of manuscript, revision of the manuscript. SJ: concept and design, editing and approval of manuscript. AD: acquisition of images, concept and design. Each author has participated sufficiently in the work to take public responsibility for appropriate portions of the content.

Funding The authors have not declared a specific grant for this research from any funding agency in the public, commercial or not-for-profit sectors.

Competing interests None declared.

Patient consent for publication Parental/guardian consent obtained.

Provenance and peer review Not commissioned; externally peer reviewed.

\section{REFERENCES}

1 Jalali S, Azad R, Trehan HS, et al. Technical aspects of laser treatment for acute retinopathy of prematurity under topical anesthesia. Indian J Ophthalmol 2010;58:509.

2 International Committee for the Classification of Retinopathy of Prematurity. The international classification of retinopathy of prematurity revisited. Archives of ophthalmology 2005;123:991.

3 Yonekawa Y, Chan RP. Widefield imaging-guided treatment of Pediatric Vitreoretinal diseases. Retina Today 2014;9:54-7.

4 Kang KB, Orlin A, Lee TC, et al. The use of digital imaging in the identification of skip areas after laser treatment for retinopathy of prematurity and its implications for education and patient care. Retina 2013;33:2162-9.

Copyright 2019 BMJ Publishing Group. All rights reserved. For permission to reuse any of this content visit

https://www.bmj.com/company/products-services/rights-and-licensing/permissions/

BMJ Case Report Fellows may re-use this article for personal use and teaching without any further permission.

Become a Fellow of BMJ Case Reports today and you can:

- Submit as many cases as you like

- Enjoy fast sympathetic peer review and rapid publication of accepted articles

- Access all the published articles

- Re-use any of the published material for personal use and teaching without further permission

For information on Institutional Fellowships contact consortiasales@bmjgroup.com

Visit casereports.bmj.com for more articles like this and to become a Fellow 